\title{
Randomised double-blind trial of acyclovir (Zovirax) and adenine arabinoside in herpes simplex amoeboid corneal ulceration
}

\author{
L M T COLlUM,' P LOGAN,' D McAUlifFE-CURTIN,' S O HUNG, ${ }^{2}$
} A PATTERSON, ${ }^{2}$ AND P J REES

From the Royal Victoria Eye and Ear Hospital, Dublin; St Paul's Hospital, Liverpool; and the Wellcome Research Laboratories, Kent.

SUMmARY Fifty-one patients were treated in a dual-centre, double-blind comparison of acyclovir and adenine arabinoside in herpetic amoeboid (geographic) corneal ulceration. Twenty-four of the 25 patients receiving acyclovir healed in a mean time of $12 \cdot 2$ days, while 24 of the 26 patients treated with adenine arabinoside healed in a mean time of 11.0 days. There was no statistically significant difference between the two groups in terms of healing. A second analysis, excluding any patients who had received antiviral treatment immediately prior to entry into the study, showed that 18 of the 19 who received acyclovir healed in an average of 11.7 days and 18 of the 19 recipients of adenine arabinoside healed in a mean time of 11.2 days. Again the difference was not statistically significant.

Acyclovir (Zovirax) is a highly selective and relatively non-toxic antiherpes agent. ${ }^{12}$ It has become a standard treatment for dendritic corneal ulceration over the past few years and is at least as effective as $^{3.5}$ or superior to $^{6-110}$ idoxuridine (IDU) and adenine arabinoside (Ara-A) and broadly similar to trifluorothymidine (TFT)". Acyclovir also has a role in the management of stromal herpetic keratitis. $^{12}$

Geographic (amoeboid) corneal ulceration is a much more difficult problem than dendritic ulceration. It is frequently associated with the previous use of corticosteroids and is often complicated by deep keratitis and anterior uveitis. Topical administration of acyclovir ophthalmic ointment has been shown to produce potentially therapeutic levels of the drug in the aqueous humour,$^{13}$ which may be of benefit in the treatment of geographic ulceration. In this paper the role of acyclovir in the management of herpetic geographic corneal ulceration is examined and its efficacy is compared with that of Ara-A.

\section{Materials and methods}

Two centres were involved in this study. Patients presenting with geographic ulcers and who gave their

Correspondence to Mr L M T Collum, FRCS, 54 Adelaide Road, Dublin 2. Ireland. informed consent were included. Each patient was randomly allocated to receive either $3 \%$ acyclovir, or $3 \%$ Ara-A in ointment form, together with cycloplegics and eye padding as appropriate. The ointments were applied five times daily until the healing of the lesions and then for a further three days. Both drugs were identically packaged and coded. Patients were seen as frequently as necessary but at least twice weekly. At each visit a full ocular examination was carried out. The ulcer was stained and its size measured, the extent and severity of any stromal reaction and uveitis were recorded, and symptoms were scored on a points basis (0-3). Healing was reached when there was no further staining of the ulcer area. Patients were withdrawn from the study if the ulcer worsened over three days or remained static for more than 10 days. Patients were to be withdrawn if any toxic signs or symptoms appeared.

The treatment groups were compared on entry for distribution of sex, ulcer size, occurrence of previous attacks, and previous therapy by $\chi^{2}$ tests. Age and symptom duration, and severity of symptoms, stromal infiltration, and uveitis were compared by MannWhitney tests. A number of patients had received antiviral treatment before entry into the study, and, as it was felt that this might prejudice the results, a separate analysis was performed by the same methods but with the exclusion of these patients. 
Table 1 Characteristics of patients at presentation

\begin{tabular}{|c|c|c|c|c|c|}
\hline & & \multicolumn{2}{|l|}{ Allpatients } & \multicolumn{2}{|c|}{$\begin{array}{l}\text { Patients with no previous antiviral } \\
\text { therapy for this attack }\end{array}$} \\
\hline & & $\begin{array}{l}\text { Adenine } \\
\text { arabinoside }\end{array}$ & Acyclovir & $\begin{array}{l}\text { Adenine } \\
\text { arabinoside }\end{array}$ & Acyclovir \\
\hline \multirow[t]{2}{*}{ Sex } & Male & 13 & 16 & 7 & 11 \\
\hline & Female & 13 & 9 & 12 & 8 \\
\hline Ulcer size & Large & 8 & 18 & 5 & 14 \\
\hline Previous attack & Percent & 52 & 40 & 42 & 42 \\
\hline Age (years) & Median & 57 & 54 & 61 & 45 \\
\hline Duration of symptoms (days) & Median & 14 & 10 & 11 & 7 \\
\hline Severity of symptoms (score) & Mean & $2 \cdot 0$ & $2 \cdot 0$ & $2 \cdot 0$ & $1 \cdot 9$ \\
\hline Stromal infiltration (score) & Mean & $1 \cdot 2$ & $1 \cdot 1$ & $1 \cdot 3$ & $1 \cdot 0$ \\
\hline Uveitis (score) & Mean & $0 \cdot 5$ & $0 \cdot 8$ & $0 \cdot 7$ & 0.9 \\
\hline \multirow[t]{2}{*}{ Previous therapy this attack } & Corticosteroid & 6 & 3 & 6 & 3 \\
\hline & Antibiotic & 4 & 8 & 3 & 8 \\
\hline
\end{tabular}

\section{Results}

Fifty-four patients entered the study. Three patients randomly allocated to acyclovir treatment failed to return after their initial assessment and were excluded from the analysis. Of the 51 remaining patients 26 received Ara-A and 25 acyclovir. Characteristics of the patients at entry are summarised in Table 1. Statistical analyses showed no significant differences between the two groups at entry, except that the acyclovir group had a significantly higher proportion of patients with large ulcers than the Ara-A group $(p<0.05)$. A number of patients were receiving corticosteroids or antibiotics on entering the study.

Three patients were withdrawn from the study owing to failure of treatment, two in the Ara-A group and one in the acyclovir group. The lesions in all the remaining patients healed. Log rank analysis of the two treatment groups showed no significant difference in healing times. The mean healing time for the Ara-A group was 11.0 days, and for the acyclovir group, $12 \cdot 2$ days $(p=0 \cdot 62$; Fig. 1$)$. Owing to the imbalance in ulcer size between the two groups at entry, an analysis with treatment and ulcer size as factors was carried out. This showed no effect of ulcer size on healing time. Previous steroid therapy for the current attack did not appear to influence healing times. The only adverse reaction noted was superficial punctate epitheliopathy in two patients receiving acyclovir and five patients receiving Ara-A.

Seven patients treated with Ara-A and six on acyclovir had received antiviral treatment immediately prior to entry into the study. It was possible that
Fig. 1 Cumulative frequency distribution of time taken to heal.

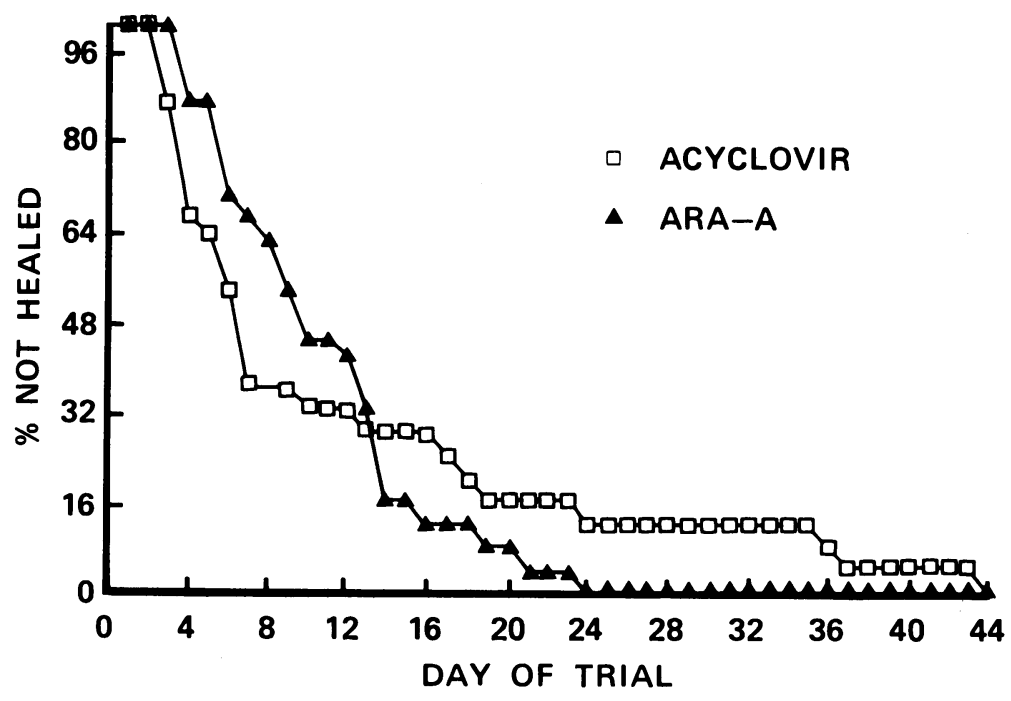




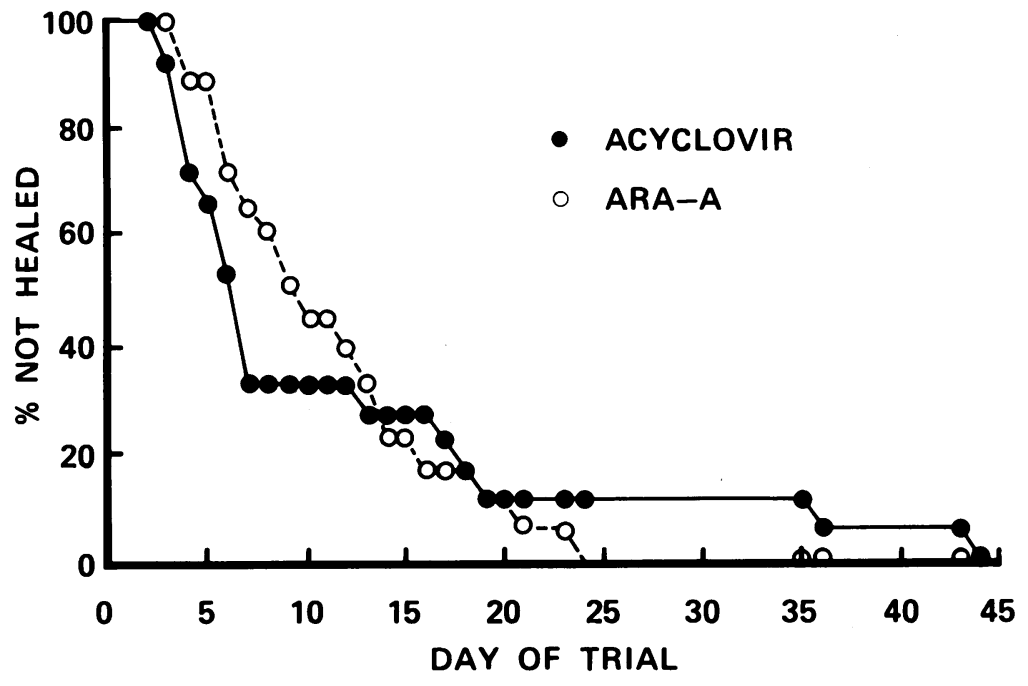

Fig. 2 Cumulative frequency distribution of time taken to heal (apart from patients with previous antiviral therapy for the current attack).

this might prejudice the results, so a separate analysis was performed with these patients excluded. The characteristics of the remaining patients are summarised in Table 1 . The acyclovir group again had a significantly higher proportion of large ulcers than the Ara-A group ( $p<0.01)$, but there were no other significant differences between the two groups at entry. The mean healing time in the Ara-A group was 11.2 days as compared with 11.7 days in the acyclovir group ( $\mathrm{p}=0 \cdot 39 ;$ Fig. 2$)$.

\section{Discussion}

Geographic corneal ulcers are difficult to treat and are associated with many complications. They frequently require more prolonged therapy than simple dendritic ulcers. Many are associated with previous corticosteroid therapy, which complicates their management. It is important therefore that these lesions are managed with an agent which can be used for as long as necessary and with no toxic effects. It is clear that prolonged treatment with IDU is associated with significant toxicity. Acyclovir should be a suitable agent because of its solubility and low incidence of toxicity.

This study has shown that acyclovir and Ara-A are effective and of equal potency in the management of geographical herpetic corneal ulceration. Healing rates were not affected by either ulcer size or the previous use of antiviral agents. The previous use of corticosteroids did not appear to influence the healing times. No significant toxic effects were recorded in either group.

Previous experience with acyclovir has not been associated with any significant side effects even when given for up to 61 days. ${ }^{14}$ Acyclovir therefore is particularly suitable for the treatment of amoeboid corneal ulceration, which frequently requires more prolonged treatment than simple dendritic ulceration.

The authors thank Mrs C Burke, of the Wellcome Research Laboratories, for assistance with the statistical analyses.

\section{References}

1 Elion GB, Furman PA, Fyfe JA, et al. Selectivity of action of an antiherpetic agent, 9-(2-hydroxyethoxymethyl) guanine. Proc Natl Acad Sci USA 1977; 74: 5716-20.

2 Schaeffer HJ, Beauchamp L, de Miranda P, et al. 9-(2hydroxyethoxymethyl) guanine activity against viruses of the herpes group. Nature 1978; 272: 583-5.

3 Coster DJ, Wilhelmus KR, Michaud R, Jones BR. A comparison of acyclovir and indoxuridine as treatment for ulcerative herpetic keratitis. BrJ Ophthalmol 1980; 64: 763-5.

4 McCulley JP, Binder PS, Kaufman HE, et al. A double-blind, multicenter clinical trial of acyclovir vs idoxuridine for treatment of epithelial herpes simplex keratitis. Ophthalmology (Rochester) 1982; 89: 1195-200.

5 Laibson PR, Pavan-Langston D, Ycakley WR, Lass J. Acyclovir and vidarabine for the treatment of herpes simplex keratitis. Am J Med 1982; 73: 281-5.

6 Collum LMT, Benedict-Smith A, Hillary IB. Randomised double-blind trial of acyclovir and idoxuridine in dendritic corneal ulceration. BrJ Ophthalmol 1980; 64: 766-9.

7 Colin J, Tournoux A, Chastel C, Renard G. Superficial herpes simplex keratitis. Double-blind comparative trial of acyclovir and idoxuridine. Nouv Presse Med 1981; 10: 2969-75.

8 Klauber A, Ottovay E. Acyclovir and idoxuridine treatment of herpes simplex keratitis-a double blind clinical study. Acta Ophthalmol (Kbh) 1982; 60: 838-44.

9 McGill J, Tormey P, Walker CB. Comparative trial of acyclovir and adenine arabinoside in the treatment of herpes simplex corneal ulcers. Br J Ophthalmol 1981; 65: 610-3. 
10 Young BJ, Patterson A, Ravencroft T. A randomised doubleblind clinical trial of acyclovir (Zovirax) and adenine arabinoside in herpes simplex corneal ulceration. Br J Ophthalmol 1982; 66: 361-3.

11 La Lau C, Oosterhuis JA, Versteeg J, et al. Acyclovir and trifluorothymidine in herpetic keratitis: a multicentre trial. $\mathrm{Br} J$ Ophthalmol 1982; 66: 506-8.
12 Collum LMT, Logan P, Ravenscroft T. Acyclovir (Zovirax) in herpetic disciform keratitis. Br J Ophthalmol 1983; 67: 115-8

13 Poirier RH, Kingham JD, de Miranda P, Annel M. Intraocular antiviral penetration. Arch Ophthalmol 1982; 100: 1964-7.

14 Collum LMT, Logan P, Hillary IB, Ravenscroft T. Acyclovir in herpes keratitis. Am J Med 1982: 73: 290-3. 